American Journal of Agricultural and Biological Sciences 3 (3): 584-590, 2008

ISSN 1557-4989

(C) 2008 Science Publications

\title{
Factors Influencing the Extent of Practice of Organic Farming Technologies: A Case Study of Tangail District in Bangladesh
}

\author{
${ }^{1} \mathrm{Md}$. Asaduzzaman Sarker and ${ }^{\mathbf{2}}$ Yoshihito Itohara \\ ${ }^{1}$ The United Graduate School of Agricultural Sciences, Tottori University, Japan \\ ${ }^{2}$ Faculty of Agriculture, Yamaguchi University, Japan
}

\begin{abstract}
The study was attempted to explore the major factors influencing the extent of practice of organic farming technologies (called OFTs from here) by the Bangladeshi farmers. The empirical data for the study were collected from the organic farmers of the selected villages of Tangail district in Bangladesh. The results of the study identified four factors like development of knowledge and awareness regarding environmental issues, creation of health awareness, and simplicity of the OFTs and availability of basic production factors as the major influential factors which can increase the extent of practice of OFTs by the farmers. Taking these factors into account the policy makers can formulate a strategy to increase the extent of practice of various OFTs by the farmers for the successful expansion of organic farming in Bangladesh.
\end{abstract}

Key words: Factors, influence, extent of practice, OFTs and Bangladesh

\section{INTRODUCTION}

The agriculture of Bangladesh has faced countless challenges like soil erosion, nutrient depletion, expansion of saline area, creation of acid sulphate soil, imbalance of nutrients in the soil, inadvertent destruction of natural enemies of pest and emergence of both pest resistance and secondary pests in the recent years. By any means, all these are directly or indirectly associated with the consequences of the so called Green Revolution ${ }^{[1]}$. On the other slide it is proved by the scientists that organic agriculture is the best form of agriculture on earth and a widely esteemed method to overcoming the harmful impacts of the Green Revolution on soil, air, water, produce, landscapes and humans globally ${ }^{[2]}$. Many countries in the world have already attained a significant development in certified organic farming where nearly 31 million ha of land are currently managed organically in 120 countries throughout the world and the market for organic foods and beverages was US\$ 40 billion in 2006 which is $2 \%$ of total food retail in the developed countries ${ }^{[3]}$. Unfortunately, in this big organic market the share of the developing countries like Bangladesh is really very little. Though many researchers like Kilcher ${ }^{[4]}$, Mc Neely and Scherr ${ }^{[5]}$ and Yussefi and Willer ${ }^{[6]}$ strongly recommended that organic agriculture is not just a resolution for more wealthy countries but also effective in poorer countries and it can give them purposeful socio-economic and ecologically sustainable development. Default organic farming (non-certified) is being practiced by the Bangladeshi farmers since early 1980s. In spite of the continuous efforts from the NGO sector for the past two decades, sadly it could not expand satisfactorily in the country ${ }^{[7]}$. Research effort is also very limited here on organic farming. Thus, the researchers take an attempt to explore the factors which are significantly influencing the extent of practice of OFTs. The present study was conducted with the following specific objectives: i) to explore the basic factors behind the extent of practice of OFTs by the farmers in Bangladesh; and ii) to assess the extent of influences of those factors in the extent of practice of OFTs by the Bangladeshi farmers.

\section{MATERIALS AND METHODS}

The required data for the study were collected from Pirojepur village of Madhupur upazila (sub-district) under Tangail district in March 2006. The rationale of selecting this village was because the majority portion of the farmers of this village are practicing organic methods with the guidance of PROSHIKA (an eminent national level NGO of Bangladesh) for more than a decade. All the default organic farmers (According to Scialabba ${ }^{[8]}$; millions of small farmers are practicing organic farming without being certified which is called

Corresponding Author: Md. Asaduzzaman Sarker, Assistant Professor, Department of Agricultural Extension Education, Bangladesh Agricultural University, Mymensingh-2202, Tel: 0081-80-3891-9955 
as organic by default) of the village were treated as the population of the study. From this population 120 default organic farmers were selected randomly and this figure constitutes the sample of the study. Face to face interviews of the respondent farmers were done with a well structured questionnaire for collecting the pragmatic data. The extent of practice of OFTs by a farmer was the dependent variable of the study and was operationalized on the basis of the extent of a farmer's use of the selected 26 OFTs among which 14 were related to fertilization and 12 were related to pest control activities. Respondents were asked to what extent they practice these 26 OFTs while managing their farm. A 4-point rating scale was used to measure the extent of practice of OFTs by the farmers. They were asked to indicate whether their extent of practice of OFTs was either high, low, or never, Points were awarded for each response, sufficient scoring as the highest (3,2, 1 and 0 respectively). A respondent's score could range from 0 to 78 , where 0 indicated never practice and 78 indicated the highest practice of the OFTs. Frequency counts of responses were also recorded to compute the Practice Index of Organic Farming Technologies (PIOFTs) the farmers for each of the organic farming technology. Practice Index of Organic Farming Technologies (PIOFTs) was computed by using the following formula:

$$
\text { PIOFTs }=\left(\mathrm{N}_{1} \mathrm{X} 3\right)+\left(\mathrm{N}_{2} \mathrm{X} 2\right)+\left(\mathrm{N}_{3} \mathrm{X} 1\right)+\left(\mathrm{N}_{4} \mathrm{X} 0\right)
$$

$$
\begin{aligned}
& \text { Here: } \\
& \text { PIOFTs }=\text { Practice Index of Organic Farming } \\
& \text { Technologies } \\
& \mathrm{N}_{1} \quad=\text { Number of farmers practice the OFT highly } \\
& \mathrm{N}_{2} \quad=\text { Number of farmers practice the OFT } \\
& \text { moderately } \\
& \mathrm{N}_{3} \quad=\text { Number of farmers practice the OFT in low } \\
& \text { amount } \\
& \mathrm{N}_{4}=\text { Number of farmers never practice the OFT }
\end{aligned}
$$

After collection of the raw data from the respondents it was coded with the appropriate numeric values and/or symbols. Afterward, these coded values were inserted into the computer to analyze descriptive statistics (i.e., frequencies, percentage and mean), principal component analysis and step-wise multiple regression analysis with the help of SPSS 11.0 version software. According to Ray et al. ${ }^{[9]}$, the principal component analysis is one sort of factor analysis which is used for the selection of a least number of meaningful and functional factors, considerably fewer in number than the original variables, which is responsible for most of the variances in the data set and convey the same information.

\section{RESULTS AND DISCUSSION}

Determinants of extent of practice of OFTs by the farmers: Explanatory variables: Sixteen explanatory variables (seven were related to individual characteristics, four were related to the access to information sources, three were related to technology characteristics and two were related to awareness regarding environmental and health hazard issues) were used as the predictors of the extent of practice of OFTs. Their measurement techniques and summary profile of the explanatory variables are presented in Table 1.

With few exceptions respondent farmers were predominantly male and more than half $(55.8 \%)$ of them with primary school education. Only, 5\% of the farmers had no education while $39.2 \%$ had secondary school education. Ages of farmers ranged from 18-80 with more than half $(60.8 \%)$ were between $18-35$ years old. Mean farm holdings of the farmers were 1.21 ha and nearly half (49.2\%) of them had small farm holdings (between 0.21-0.99 ha). Family labor size was distributed over a range of 3-11 members with an average of 5.08 members. Annual agricultural income of the respondent farmers ranged between 8 thousand to 125 thousand BDT. The majority $(91.6 \%)$ were low to medium income. Mean organic farming experience was 2.93 years and $50 \%$ of them had been farming organically for 3-5 years. Where as only $4.2 \%$ of the farmers had been farming organically for more than 5 years. The knowledge of organic farming score of the majority farmers $(72.5 \%)$ was moderate (in between 610). On the other hand, 5\% farmers had good knowledge and only $1.7 \%$ had excellent knowledge on different aspects of organic farming. Table 1 shows the absolute majority (97.5\%) of the farmers had individual media contact where as majority farmers' group and mass media contact was low. The mean environmental awareness score of the organic farmers was 8.13 and utter majority $(89.1 \%)$ of the farmers had low to medium level environmental awareness while only $10.9 \%$ of the farmers had high environmental awareness. Likewise, more than half $(59.2 \%)$ of the farmers had medium level health awareness with an average score of 5.88. Three characteristics (i.e., relative advantages, simplicity and observability) of the selected 26 OFTs having influence on the extent of 
practice were considered in this study. Results of the study showed that almost all of the farmers had a Table 1: Methodological aspects and summary profile of the explanatory variables

\begin{tabular}{|c|c|c|c|c|c|}
\hline \multirow{2}{*}{$\begin{array}{l}\text { Explanatory variables with } \\
\text { measurement techniques }\end{array}$} & \multirow[b]{2}{*}{$\begin{array}{l}\text { Observed } \\
\text { range }\end{array}$} & \multirow[b]{2}{*}{$\begin{array}{l}\text { Distribution of the farmers based } \\
\text { on their characteristics }\end{array}$} & \multicolumn{3}{|c|}{ Organic farmers $(\mathrm{N}=120)$} \\
\hline & & & $\mathrm{f}$ & $(\%)$ & Mean \\
\hline \multirow[t]{3}{*}{ Age (Number of years) } & \multirow[t]{3}{*}{$18-80$} & Young (18-35) & 73 & 60.80 & \multirow[t]{3}{*}{38.83} \\
\hline & & Middle aged (36-45) & 18 & 15.00 & \\
\hline & & Old (46 and above) & 29 & 24.20 & \\
\hline \multirow[t]{3}{*}{ Educational level (Years of schooling) } & \multirow[t]{3}{*}{$0-10$} & Non-educated (0) & 6 & 5.00 & \multirow[t]{3}{*}{4.79} \\
\hline & & Primary passed (1-5) & 67 & 55.80 & \\
\hline & & Secondary passed (6-10) & 47 & 39.20 & \\
\hline \multirow{3}{*}{$\begin{array}{l}\text { Family labor size (Number of family } \\
\text { members } 14+\text { years old) }\end{array}$} & \multirow[t]{3}{*}{$3-11$} & Small family labor (2-4) & 50 & 41.70 & \multirow[t]{3}{*}{5.08} \\
\hline & & Medium family labor (5-7) & 61 & 50.80 & \\
\hline & & Large family labor ( 8 and above) & 9 & 7.50 & \\
\hline \multirow[t]{4}{*}{ Farm holdings (Amount in hectare) } & \multirow[t]{4}{*}{$0.16-6.45$} & Marginal farm holdings $(0.02-0.20)$ & 1 & 0.80 & \multirow[t]{4}{*}{1.21} \\
\hline & & Small farm holdings $(0.21-0.99)$ & 59 & 49.20 & \\
\hline & & Medium farm holdings (1.00-2.99) & 56 & 46.70 & \\
\hline & & Large farm holdings (above 3.00 ) & 4 & 3.50 & \\
\hline \multirow{4}{*}{$\begin{array}{l}\text { Annual agricultural income } \\
\text { ('000’ BDT; } 1 \mathrm{US} \$=67 \mathrm{BDT} \text { ) }\end{array}$} & \multirow[t]{4}{*}{$8-125$} & Very low income (up to 10 ) & 2 & 1.70 & \multirow[t]{4}{*}{27.50} \\
\hline & & Low income (11-25) & 52 & 43.30 & \\
\hline & & Medium income (26-50) & 58 & 48.30 & \\
\hline & & High income (more than 50) & 8 & 6.70 & \\
\hline \multirow{4}{*}{$\begin{array}{l}\text { Knowledge of organic farming } \\
\text { (Assessment score) }\end{array}$} & $4-16$ & Poor knowledge (up to 5) & 25 & 20.00 & 7.22 \\
\hline & & Moderate knowledge (6-10) & 87 & 72.50 & \\
\hline & & Good knowledge (11-15) & 6 & 5.00 & \\
\hline & & Excellent knowledge (above 15) & 2 & 1.70 & \\
\hline Organic farming experience & $2-6$ & Low experience (up to 2 ) & 55 & 45.80 & 2.93 \\
\hline (Number of years) & & Medium experience (3-5) & 60 & 50.00 & \\
\hline & & High experience (above 5) & 5 & 4.20 & \\
\hline Individual media contact (Scoring) & $3-26$ & Low individual media contact (up to10) & 7 & 5.80 & 16.49 \\
\hline & & Medium individual media contact (11-20) & 92 & 76.50 & \\
\hline & & High individual media contact (above 20) & 21 & 17.50 & \\
\hline Group media contact (Scoring) & $1-12$ & Low group media contact (up to10) & 117 & 97.50 & 5.47 \\
\hline & & Medium group media contact $(11-20)$ & 3 & 2.50 & \\
\hline & & High group media contact (above 20) & 0 & 0.00 & \\
\hline Mass media contact (Scoring) & $0-22$ & Low mass media contact (up to 8 ) & 74 & 61.70 & 7.78 \\
\hline & & Medium group media contact (9-16) & 44 & 36.60 & \\
\hline & & High mass media contact (above 16) & 2 & 1.70 & \\
\hline Attachment with NGO (Dummy) & - & Attached with NGO & 60 & 50.00 & \\
\hline & & Not attached with NGO & 60 & 50.00 & \\
\hline Relative advantages of the OFTs & $2-16$ & Low relative advantage (up to 8 ) & 56 & 46.67 & 9.12 \\
\hline (Scoring) & & Medium relative advantage (9-17) & 64 & 53.33 & \\
\hline & & High relative advantage $(>16)$ & 0 & 0.00 & \\
\hline Simplicity of the OFTs (Scoring) & $1-9$ & Low simplicity (up to 8 ) & 119 & 99.17 & 4.05 \\
\hline & & Medium simplicity (9-17) & 1 & 0.83 & \\
\hline & & High simplicity $(>16)$ & 0 & 0.00 & \\
\hline Observability of the OFTs (Scoring) & $1-6$ & Low observability (up to 8) & 120 & 100.00 & 2.87 \\
\hline & & Medium observability (9-17) & 0 & 0.00 & \\
\hline & & High observability (> 16) & 0 & 0.00 & \\
\hline Environmental awareness (Scoring) & $3-14$ & Low awareness (up to 5) & 7 & 5.80 & 8.13 \\
\hline & & Medium awareness (6-10) & 100 & 83.30 & \\
\hline & & High awareness (Above 10) & 13 & 10.90 & \\
\hline Health awareness (Scoring) & $3-8$ & Low awareness (up to 5) & 7 & 5.80 & 5.88 \\
\hline & & Medium awareness (6-10) & 100 & 83.30 & \\
\hline & & High awareness (Above 10) & 13 & 10.90 & \\
\hline
\end{tabular}

feeling that the selected 26 OFTs had low to medium level relative advantages where more than half $53.33 \%$ of the farmers had a feeling that 26 OFTs had medium relative advantages. On the contrary, almost all the farmers had a feeling that the selected 26 OFTs have low level simplicity and observability.
Major factors working behind the extent of practice of OFTs: The principal component analysis was used

in order to discover the factors influential to the extent of practice of OFTs by the farmers. For this purpose of the principal component analysis, the responses of the respondents regarding the 16 independent variables were taken into consideration. The results of the principal component analysis are presented in Table 2. 
Factor 1: Development of knowledge and awareness regarding environmental issues: Factor 1 is accounted

Table 2: Rotated factor matrices of the sixteen explanatory variables along with factor loadings

\begin{tabular}{|c|c|c|c|c|c|c|}
\hline \multirow[b]{2}{*}{ Variables } & \multicolumn{5}{|c|}{ Factors } & \multirow{2}{*}{$\begin{array}{c}\text { Communality } \\
\mathrm{h}^{2}\end{array}$} \\
\hline & 1 & 2 & 3 & 4 & 5 & \\
\hline$\overline{X_{1} \text { Age }}$ & -0.388 & -0.151 & 0.5870 & 0.103 & 0.304 & 0.622 \\
\hline $\mathrm{X}_{2}$ Educational level & 0.643 & 0.394 & 0.0730 & -0.063 & 0.037 & 0.579 \\
\hline $\mathrm{X}_{3}$ Family labor size & 0.596 & 0.082 & -0.3200 & 0.027 & 0.436 & 0.656 \\
\hline $\mathrm{X}_{4}$ Farm holdings & 0.421 & 0.254 & -0.0630 & 0.690 & -0.155 & 0.745 \\
\hline $\mathrm{X}_{5}$ Annual agricultural income & 0.633 & 0.356 & 0.2690 & 0.367 & -0.087 & 0.741 \\
\hline $\mathrm{X}_{6}$ Knowledge of organic farming & 0.598 & 0.121 & -0.3130 & -0.294 & 0.087 & 0.565 \\
\hline $\mathrm{X}_{7}$ Organic farming experience & 0.756 & -0.116 & -0.0820 & -0.226 & 0.152 & 0.665 \\
\hline $\mathrm{X}_{8}$ Individual media contact & 0.570 & -0.380 & 0.1260 & 0.245 & -0.217 & 0.593 \\
\hline $\mathrm{X}_{9}$ Group media contact & 0.637 & 0.023 & 0.1240 & -0.169 & -0.128 & 0.467 \\
\hline $\mathrm{X}_{10}$ Mass media contact & 0.103 & 0.729 & 0.1360 & -0.096 & 0.232 & 0.623 \\
\hline $\mathrm{X}_{11}$ Attachment with NGO & 0.663 & -0.597 & 0.0880 & 0.109 & -0.164 & 0.842 \\
\hline $\mathrm{X}_{12}$ Relative advantages of OFTs & 0.581 & -0.068 & 0.1990 & -0.331 & -0.398 & 0.623 \\
\hline $\mathrm{X}_{13}$ Simplicity of OFTs & 0.348 & 0.073 & 0.5700 & -0.329 & -0.104 & 0.571 \\
\hline $\mathrm{X}_{14}$ Observability of OFTs & 0.354 & -0.181 & 0.4050 & 0.077 & 0.532 & 0.610 \\
\hline $\mathrm{X}_{15}$ Environmental awareness & 0.702 & -0.127 & -0.2240 & 0.106 & 0.231 & 0.623 \\
\hline $\mathrm{X}_{16}$ Health awareness & 0.019 & 0.618 & 0.0710 & 0.005 & -0.271 & 0.461 \\
\hline Eigenvalues or Latent root & 4.684 & 1.877 & 1.2500 & 1.107 & 1.069 & \\
\hline Percent of variance explained by each factor & 29.274 & 11.729 & 7.8110 & 6.919 & 6.683 & \\
\hline Cumulative percent of variance & 29.274 & 41.004 & 48.8150 & 55.733 & 62.416 & \\
\hline
\end{tabular}

Source: Own analysis

for $29.27 \%$ of the total data variability (percent of variance explained by each factor). Five variables with high factor loadings and high communality were chosen to interpret this factor. The variables and their factor loadings were:

$\mathrm{X}_{7} \quad$ Organic farming experience 0.756

$\mathrm{X}_{15}$ Environmental awareness $\quad 0.702$

$\mathrm{X}_{11}$ Attachment with NGO 0.663

$\mathrm{X}_{2}$ Educational level $\quad 0.643$

$\begin{array}{lll}\mathrm{X}_{9} & \text { Group media contact } \quad 0.637\end{array}$

Farmers' knowledge and awareness on environmental issues have definite and clear-cut impact on their extent of practice of different OFTs. Farmers having higher knowledge and awareness regarding environmental problems are always eager to practice agricultural technologies that are friendly to the environment. A study of McCann et al. ${ }^{[10]}$ noted, organic farmers express a greater awareness and concern for environmental problems associated with agriculture that helps in understanding the reality that it is essential to increase knowledge and awareness regarding environmental issues. To understand the environmental hazardous situation due to over use of agro-chemicals knowledge and awareness is very crucial. Naturally, highly educated farmers are much aware regarding these issues rather than non-educated and less educated farmers. Along with education, farmer's long time experience of using environmentally friendly agricultural technologies as well as their participation in different group activities (like training, demonstration, group discussion) also contributes significantly in developing farmers' knowledge and awareness regarding environmental problems. Consequently this factor affects the extent of practice of OFTs by the farmers.

Factor 2: Creation of health awareness: This factor accounted for $11.73 \%$ of the total variability. Three variables were chosen for interpretation of the factor. The variables and their factor loadings were:

$\mathrm{X}_{10}$ Mass media contact $\quad 0.729$

$\mathrm{X}_{16}$ Health awareness $\quad 0.618$

$\mathrm{X}_{3}$ Educational level $\quad 0.394$

Health awareness and consumption of safe foods are related to each other. An individual having awareness regarding health issues always try to take food that is safe for his health. It means that people who are aware regarding his personal health has greater preference of organic food than traditional one. As most of the farming enterprises in Bangladesh are linked with family subsistence thus farmers with health awareness wants to practice OFTs for producing safe food for their own consumption. However, it is well established that for creating health awareness mass media (electronic and print media) can play the pivotal role. If the mass media of the country take the initiative to create awareness among the farmers regarding the potential 
health hazards and the harmful effects of the food that are grown with agro-chemicals this may motivate the farmers to shift towards organic farming from traditional. As the educated farmers are the best users of mass media so the educated farmers are more conscious regarding health issues than non-educated people. Thus it is essential to take initiative to increase health awareness among the farmers through non-formal education and making available the mass media to the majority of the farmers.

Factor 3: Simplicity of the OFTs: Factor 3 accounted for $7.81 \%$ of the total data variability. On the basis of high factor loading and high communality, two variables were chosen to interpret this factor. The variables and their factor loadings were:

$\begin{array}{lll}\mathrm{X}_{1} & \text { Age } & 0.587 \\ \mathrm{X}_{13} & \text { Simplicity of the OFTs } & 0.570\end{array}$

The factor like simplicity of the OFTs is very crucial to increase the extent of adoption or practice of that particular organic technology or a package of several technologies. In 1999 a Kenyan study ${ }^{[11]}$ also confirmed that relatively high complexity and risk had significant negative influence on the speed of adoption. The organic technologies that have relatively less complexity are reasonably better practiced by the farmers. On the contrary, complex technologies are relatively less practiced by the farmers. However, the ability to understand the simplicity of a technology, farmers requires maturity and experience. Thus, mature and experienced farmers can easily assess the degree of simplicity of a technology in a better way than the young farmers who have relatively less experience in farming.

Factor 4: Availability of basic production factors: Factor 4 accounted for $6.92 \%$ of the total data variance. On the basis of high factor loading and communality, two variables were chosen to interpret this factor. The variables and their factor loading were:

$\mathrm{X}_{4}$ Farm holdings $\quad 0.690$

$\mathrm{X}_{5}$ Annual agricultural income $\quad 0.367$

Similar to any other production systems organic farming also requires basic production factors like land and capital. The study of Mesiner ${ }^{[12]}$ also supported that farm holdings is an imminent determinant in case of practicing organic farming. He has conducted a study in Bangladesh and clearly mentioned that growers that do have the ability to add organics to their land are those who are richer and have larger land holdings. Another important production factor is capital that farmers usually collect from their various agricultural incomes. With this capital they can practice organic farming with the intention of better earning. Whereas, poor farmers could not dare to take the risk of testing a new and risky technology like organic farming. Thus farmers having large farm holdings and higher agricultural income can easily take the risk to practice organic cultivation methods.

Factor 5: Observable remuneration: Factor 5 accounted for $6.68 \%$ of the data variance. Two variables were chosen for interpretation of this factor. The variables and its factor loadings were:

$\mathrm{X}_{14}$ Observability of the OFTs $\quad 0.532$

$\mathrm{X}_{3}$ Family labor size $\quad 0.436$

If the farmers can observe the benefits of a technology with the naked eyes and are able to understand that it will give them more advantages than the traditional technologies then the practice of the new technology will be undoubtly higher. At the same time farmers will check the benefits available in his/her hands to practice the technology. As organic farming is a labor intensive technology so farmers will check the availability of labor forces before starting to practice it. Thus farmers having large family labor size are in an advantageous condition compared to others.

Strength of influences of the factors in explaining the extent of practice of OFTs by the farmers: Step wise multiple regressions were done to learn the degree of relationships or strength between the extent of practice of the OFTs and the factors behind it and the results of this analysis indicate that four factors out of five finally entered into the model and jointly explained $68.6 \%$ of variation in the dependent variable (Table 3 ).

Development of knowledge and awareness regarding environmental issues: The first factor to enter the stepwise multiple regressions was development of knowledge and awareness which solely had the highest contribution of $28.7 \%$ in predicting the extent of practice of OFTs. It is proved by the scientists that organic farming is the best alternative to overcome the challenges of environmental degradation associated with traditional chemical based agriculture. If it is possible to generate knowledge among the farmers regarding the consequences of agro-chemicals used in the agriculture and make them completely aware that 
they have to adopt environmentally friendly condition as well as provide good health and extra technologies that will improve the environmental income only then the adoption of the OFTs will be Table 3: Summary of the stepwise multiple regression analysis showing contribution of the factors on the farmer's extent of practice of OFTs

\begin{tabular}{|c|c|c|c|c|c|c|}
\hline Model & Combination of the factors & $\begin{array}{l}\text { Co-efficient of } \\
\text { determination }\end{array}$ & $\begin{array}{l}\text { Adjusted } \\
\mathrm{R}^{2}\end{array}$ & $\begin{array}{l}\text { Percent of } \\
\text { increase in } \\
\text { adjusted } \mathrm{R}^{2}\end{array}$ & t-value & F-value \\
\hline 1 & $\begin{array}{l}\text { Constant }+ \text { development of knowledge and } \\
\text { awareness regarding environmental issues }\end{array}$ & 0.293 & 0.287 & 28.7 & $6.99 * *$ & $48.96^{* * *}$ \\
\hline 2 & $\begin{array}{l}\text { Constant }+ \text { development of knowledge and awareness } \\
\text { regarding environmental issues }+ \text { creation of health awareness }\end{array}$ & 0.557 & 0.550 & 26.3 & $8.36 * *$ & $73.69 * *$ \\
\hline 3 & $\begin{array}{l}\text { Constant }+ \text { development of knowledge and awareness regarding } \\
\text { environmental issues }+ \text { creation of health awareness }+ \text { simplicity of OFTs }\end{array}$ & 0.681 & 0.673 & 12.3 & $6.70 * *$ & $82.48 * *$ \\
\hline 4 & $\begin{array}{l}\text { Constant }+ \text { development of knowledge and awareness regarding } \\
\text { environmental issues }+ \text { creation of health awareness }+ \text { simplicity } \\
\text { of OFTs }+ \text { availability of basic production factors }\end{array}$ & 0.697 & 0.686 & 1.3 & $2.46 * *$ & $66.05 * *$ \\
\hline
\end{tabular}

increased automatically. Thus it is essential to take immediate steps about generation of knowledge and awareness among the farmers regarding environmental issues.

Creation of health awareness: The second factor to enter stepwise multiple regressions was the creation of health awareness, which contributed $26.3 \%$ in predicting extent of practice of OFTs. People who are conscious about personal health hazard issues have an attraction to safe food. Usually farmers in Bangladesh cultivate various crops basically for their family consumption. After meeting the family demand they sell the surplus foods. So, if we can generate health awareness among the farmers in that case they will be more curious to practice the OFTs so that they can grow safe food for their own consumption only following the methods of organic cultivation. Thus it is also important to generate awareness among the farmers regarding health issues to increase the extent of practice of OFTs among them.

Simplicity of the OFTs: The third factor was simplicity of the technologies, which contributed $12.3 \%$ in predicting the extent of practice of OFTs. The rate of adoption of the simple technologies is always higher. When making decision regarding whether to start practice of a technology, farmers first consider whether the technology is easy or complex. In most of the cases complex technologies are in the list of disliked by the farmers. As the farmers always need fertilizing and pest control technologies to manage their farms so the research and extension personnel should be more considerate to provide them with simple OFTs. Thus through timely supply of simple OFTs, the extent of practice of OFTs might be increased by the farmers.
Availability of basic production factors: The fourth explanatory variable was the Availability of basic production factors and it contributed $1.3 \%$ in predicting the extent of practice of OFTs. Availability production factors are strongly associated with the affordability of a technology by a farmer. If the farmer does not have the sufficient land and required amount of capital to practice a specific technology then the extent of practice of that technology will not be adequate. Resource poor farmers have to fight for their existence all of the time. It is impossible for them to think about the adoption of a new technology in which even a minimum amount of risk is involved. On the contrary farmers having the availability of basic production factors like land and capital have the opportunity to take the risk of testing a new technology. Thus availability of basic production factors to the farmers is also an important factor behind the extent of practice of the OFTs. So it will be technically sound to take the program for the large farmers (resource rich farmers) at first to practice OFTs. By turns small and marginal farmers might be included under the organic farming program to practice the OFTs.

\section{CONCLUSIONS}

The results of the principal component analysis and stepwise multiple regression revealed four important factors which can significantly influence the extent of practice of OFTs by the farmers in Bangladesh. These factors are: development of knowledge and awareness among the farmers regarding environmental issues; creation of health awareness; availability of simple organic farming technologies; and availability of resources. So, it can be concluded that the Department of Agricultural Extension (DAE) should take intensive program for creating awareness among the farmers regarding the negative impacts of the non-judicious use 
of agro-chemicals in agriculture. At the same time DAE should concentrate on introducing low-cost and simple OFTs to the farmers that might increase the extent of practice of the OFTs by the farmers in Bangladesh. Finally, taking into account the above mentioned factors the Government of Bangladesh need to set up a "National Organic Farming Policy" which will work to minimize the problems associated with organic farming as well as help in its rapid expansion in the country.

\section{REFERENCES}

1. Halim, A. and M.Z. Rahman, 2002. Environmental Issues in the context of NAEP. In: Proceedings of the National Workshop on Implementation of the New Agricultural Extension Policy: Achievements and Constraints, January 26-28, pp: 66-79.

2. Christian, R.V., L. Kilcher and H. Schmidt, 2005. Are standards and regulations of organic farming moving away from small farmers' knowledge? J. Sustainable Agric., 26 (1): 5-26.

3. Willer, H. and M. Yussefi, 2007. The World of Organic Agriculture-Statistics and Emerging Trends 2007. International Federation of Organic Agriculture Movements IFOAM, Bonn, Germany and Research Institute of Organic Agriculture FiBL, Ackerstrasse, Switzerland.

4. Kilcher, L., 2002. Production and trade constraints of organic products from developing countries. In: Proceedings of the 14th IFOAM Organic World Congress, August 2002, pp: 23.

5. Mc Neely, J.A. and S.J. Scherr, 2002.Eco Agriculture-Strategies to Feed the World and Save Wild Biodiversity. Island Press, Washington, USA.

6. Yussefi, M. and H. Willer, 2003. The World of Organic Agriculture Statistics of 2003 and Future Prospects. Retrieved from www.ifoam.org,on April 10, 2007.

7. Proshika, 2004. Ecological Agriculture Program of PROSHIKA: Web-Edition 2004. Retrieved from http://www.proshika.org/ar_2003_04/eap.htm, on November 02, 2006.

8. Scialabba, N., 2000. Factors influencing organic agriculture policies with a focus on developing countries. Paper presented at the Scientific Conference of IFOAM (International Federation of Organic Agricultural Movements) in Basel, Switzerland, August 28-31.

9. Ray, G.L. and S. Mondal, 1999. Research Methods in Social Sciences and Extension Education. Naya Prokash, Calcutta, India, pp: 167.

10. Mc Cann, E., S. Sullivan, D. Erickson and R. De Young, 1997. Environmental awareness, economic orientation and farming practices: A comparison of organic and conventional farms. Environ. Manage, 21: 747-758.

11. Batz, F.J., K.J. Peters and W. Janssen, 1999. The influence of technology characteristics on the rate and speed of adoption. Agric. Econ., 21: 121-130.

12. Mesiner, C., 2007. Organic Agriculture and the Global Food Supply. Retrieved from http://www.cosmosmagazine.com/node/1601, on October 05, 2007. 